\title{
The research status of flash flood warning in China
}

\author{
Zhao Keke, Peng Dingzhi, Gu Yu, Fan Chuting \\ College of Water Sciences, Beijing Normal University, Beijing 100875, China
}

\begin{abstract}
The article discusses from the disaster mechanism of flash flood to the current situation of early warning system. The formation of flash flood is closely related to rainfall intensity, underlying surface conditions and antecedent soil moisture content, and analysis of the physical process of flash flood disasters is crucial for the study of flash flood warning. Flash flood disaster warning indexes are mainly divided into two types: rainfall warning index and water level warning index. Data-driven statistical induction method and hydro-hydraulic methods based on physical mechanisms are used to determine rainfall warning index; The water level warning index can be directly determined by the upstream and downstream corresponding water level method or by the disaster water level. And summed up the current situation and development trend of China's flash flood warning research.
\end{abstract}

\section{Introduction}

Global climate change leads to frequent occurrence of extreme climatic events such as Drought, flood, snow disaster and so on, the scale is large and it appears continuously in a short time. Among them, flood disasters are one of the most frequent and most serious natural disasters in the world. Against the background of persistent global climate anomalies, the annual average economic loss of floods in China is nearly 100 billion yuan, and there is a trend of increasing year by year ${ }^{[1]}$. Among them, the death from mountain torrents in mountainous watersheds, the number of missing persons accounted for $60 \%$ to $80 \%$ of the deaths from floods and the number of missing persons, and the highest in 2010, reaching 92\% ${ }^{[2]}$.Moreover, China's flash flood disasters are widely distributed, occurrence frequently, and strong sudden. This disaster involves 30 provinces, 305 cities and 2138 county-level units, and ranks among the top in the world in terms of activity intensity, scale of outbreak, economic loss, and casualties [ 3].In recent years, China has accelerated the study of the characteristics and causes of flash flood disasters. Because it has the characteristics of difficulties in prediction and prevention, rapid formation of disasters, strong destructiveness, strong seasonality and obvious regionality ${ }^{[4]}$, We can't stop the occurrence of flash floods, but we can avoid or minimize the loss of casualties and property. He Bingshun et al. believe that the most effective means of responding to flash flood disasters at present is early warning, combined with disaster prevention engineering measures and non-engineering measures to release disaster information or warnings to organizations and individuals who may be threatened by flash floods, and transmit and execute early evacuation and transfer instructions to avoid or reduce disaster risks.

\section{Causes of flash flood disasters}

\subsection{Composition of flash flood disasters system}

In 1991, Shi Peijun ${ }^{[5]}$ proposed the concept of "Disaster hazard factors, disaster-bearing bodies and disaster-prone environments form a disaster system". Later, he refined and improved the comprehensive disaster research method and the theoretical system of the "regional disaster system", and also provided a reference for the study of the mountain flood disaster warning system ${ }^{[6-9]}$. Wei Yiming et al. ${ }^{[10]}$ believe that the flash flood disaster system consists of three factors: the factors inducing flash floods (disaster hazard factor), the environment in which the flash floods are formed (disaster-prone environment) and the flood inundation areas with human settlement or distribution of social property (disaster-bearing body). The disaster-prone environment includes the atmospheric environment, the hydro-meteorological environment and the underlying surface environment; The disaster hazard factor include heavy rain, tsunami, ice and snow ablation, dam break, reservoir flood and so on; The disaster-bearing body can be divided into people, agriculture, forestry, animal husbandry and so on. The disaster hazard factor, the disaster-prone environment, and the disaster-bearing body interact and connect with each other to form a complex system with certain structure, function and characteristics, which is what we usually call a flash flood disaster.

\subsection{Factors affecting flash flood disasters}

The flood is a phenomenon of water flow caused by the rapid increase of the amount of seawater in the rivers and lakes or the rapid rise of the water level caused by natural factors such as heavy rain, ice-skating skiing or storm 
surge. As the name suggests, the flash flood are the sudden floods in the mountain creeks. The flash floods are sudden, the water flow concentration is large, the scouring and destructive power is strong, and the water flows with silt and even stones. Not all mountain torrents will cause flash flood disaster, Only when the rapidly growing water level or flow rate exceeds the critical water level or critical flow rate during the occurrence of flash floods, it continues to grow rapidly with rapid momentum, causing floods to overflow the river farms and wash the surrounding farmland and villages, this floods that cause casualties and property losses are called flash flood disasters and are generally classified into storm flash floods, snowmelt flash floods, and glacier flash floods. The direct cause of the separation of "flash flood" from "floods" was the frequent floods in 2002, with $80 \%$ of deaths caused by flash flood disasters in the country. China's flash flood disasters are wide-ranging, with obvious multiple, disorderly sudden and strong destructive, and the defense is very difficult. Therefore, China's research on flash flood disasters is very important.

The most direct cause of flash flood disasters is precipitation. There are many sudden local rainstorms in flood-prone areas, and the climatic and topographic conditions that form the heavy rains in the hills are the main causes of flood disasters, and the influence of underlying surface conditions and human factors has played a role in promoting the formation of flash flood disasters. The outbreak of flash floods can be caused by a combination of hydro-meteorological, topographic and other factors, for example, the northern part of the Shajingzi Irrigation District in Xinjiang is dependent on the Tianshan branch, and the southern part of the irrigation area is relatively flat and low, the relative height difference is very wide. The vertical change of the climate is more significant, and the meteorological disasters are diverse. This kind of landform makes the flood potential strong, rapidly forming a flood peak and inducing flash flood disasters. And special geological structures are prone to cause serious soil erosion, and it is more likely to exacerbate flash flood disasters ${ }^{[11]}$.It can also be dominated by one of the factors to form a mountain torrent, for example, In Zhejiang Province of China, a large-scale plum rain flood often occurs, because of the alternating cold and warm air in the south of the Yangtze River, it is prone to persistent rainfall, namely plum rain. The plum rain weather lasts for 3 to 7 days, with the large range and relatively small rainfall intensity ${ }^{[12]}$; Hezheng County of Gansu Province with high altitude is located at the intersection of the Loess Plateau and the Qinghai-Tibet Plateau, due to the serious soil erosion in Hezheng County, the terraces on both sides of the strait are loosely piled up by unconsolidated erosive deposits. The impact resistance is poor. The flow of rivers is usually small, and the drought years are often interrupted, but when it comes to the annual flood season, floods are flooding ${ }^{[13]}$.

\subsection{Disaster process}

The professional English translation of Chinese vocabulary "Shanhong" is"flash"flood, which fully reflects the characteristics of the flash flood: rapid. Before the floods are formed, heavy rainfall will cause rapid runoff in the small watersheds of the hills, and then merge with the water flows in the rivers, if the flow in the exit section of the basin exceeds the warning flow, the flood will overflow the river and form a flood disaster. The flash flood warning system needs to issue an early warning before sufficient rainfall is reduced and through the slope convergence to form a flash flood, which is different from the flood forecasting system. In areas where there is no data or lack of data, flash flood warning can only obtain the critical rainfall of storms through flood warning and flooding. The process of early warning of flash floods in China generally uses the process of flood flooding to estimate the process of corresponding heavy rain.

\section{$3 \quad$ Warning index}

China's vast territory, geological landforms, rich vegetation and soil types, climate and hydrological conditions and other basic data are of varying degrees. Therefore, corresponding to different flood conditions, there are many methods for determining the early warning indexes of flash flood disasters in China, and the influencing factors of each method are different. According to the current main literature and application, the early warning indexes of flash flood disasters in China mainly include rainfall warning indexes and water level/flow warning indexes.

\section{1 rainfall warning indexes}

The research methods of rainfall warning indicators are mainly divided into two categories, data-driven statistical induction method and hydro-hydraulic methods based on physical mechanisms.

(1) data-driven statistical induction method

The statistical induction method does not consider the physical mechanism of rainfall runoff, but simply derives the critical rainfall from the disaster-stricken flood data in the disaster area. The method is simple and convenient to apply, but its credibility is not high, and the critical rainfall obtained by this method is initially Values cannot be directly applied and need to be further confirmed in conjunction with expert experience. However, when China has not carried out in-depth research on the hydrohydraulic methods, the statistical induction method is the main application method in the actual flash flood warning system. The National Mountain Flood Disaster Prevention and Control Planning Leading Group issued the $<<$ National Mountain Flood Disaster Prevention and Control Plan - Summary and Calculation Rules for Critical Rainfall of Mountain Flood Disasters (Trial) $>>$ issued in December 2003, detailing the disaster case investigation method, disaster and rainfall frequency analysis method, and also introduces the minimum rainfall from the maximum mean surface rainfall and the maximum single-station rainfall of previous flash floods to estimate the critical rainfall and regional critical rainfall, combined with interpolation method and analogy method, the critical rainfall in the data-free area can be calculated. 
Later, Chen Guiya et al. ${ }^{[14]}$, Li De et al. ${ }^{[15]}$ and Fan Jianyong et al. ${ }^{[16]}$ proved that the method proposed in the $<<$ Rules $>>$ is feasible through the analysis of typical area examples and the practical application of some provinces in national flash flood disaster planning. On the basis of summarizing the previous researches and using the research results of the $<<$ Rules $>>$, Cheng Weishuai ${ }^{[17]}$ believes that the critical rainfall indicators obtained by different statistical induction methods in the same area are not consistent, in most cases, the initial critical rainfall values cannot be directly applied, and it is necessary to be further confirmed in conjunction with expert experience.

(2) hydro-hydraulic methods based on physical mechanisms

The hydro-hydraulic method is based on the hydrological process and hydraulic process formed by flash flood disasters. There are many data requirements in this method, and there are corresponding requirements for disasters, rainfall, underlying surface conditions, runoff, and river characteristics. The process of using the hydrohydraulic method to estimate the critical rainfall is to use the flood to estimate the heavy rain process. It is known that the flood water level/flow leads to the rainfall during the corresponding period of the flood, that is, the critical rainfall. In this calculation or simulation process, the most important thing is to carry out river flood calculations (water level-flow relationship) and watershed production and sink calculations. The water level-flow backcalculation method, the model method, and the statistic method of storm data statistical parameters are all hydrohydraulic method. They all use hydrological and hydraulic theoretical calculating formula to some extent.

Ye Yong et al. ${ }^{[18]}$ proposed to push the warning flow through the warning water level of the control section in 2008. Combined with the small watershed with no measured heavy rain data, the design heavy rain process of each frequency can be calculated according to 《short duration rainstorm in Zhejiang Province》 and the flood process can be calculated according to unit line method. The critical rainfall of the $1 \mathrm{~h}, 3 \mathrm{~h}$, and $6 \mathrm{~h}$ warning periods at each storm frequency is obtained. This is the earliest level-flow back-calculation method. Floods are used to estimate heavy rain. Although the influence of soil moisture content on critical rainfall is not considered, many researchers have adopted the idea of reverse thrust to make the research of critical rainfall in China flourish. In 2010, Liu Zhiyu ${ }^{[19]}$ used the flash flood guidance (FFG) method developed by the American Hydrological Research Center to propose that using the rainfall that has occurred in small watersheds to simulate the flooding process of the study area by the GBHM model. And count the rainfall that the peak flow of the outlet section of the watershed required at different time scales $(1,3,6,12,24$ h) under different soil saturations $(25 \%, 50 \%, 75 \%)$ to reach the wainingflow. This rainfall is called "FFG value" or dynamic critical rainfall. The value of the warning flow here needs to be reversed from the water level and flow. Afterwards, the research on the dynamic critical rainfall considering the soil moisture content has gradually increased. In 2012, Ye Jinyin et al. ${ }^{[20]}$ used the Xin'anjiang model to simulate the flow of the river basin. According to whether the flood process exceeded the warning flow, the flood was divided into super police and no police. In the two categories, the linear relationship between dynamic critical rainfall and soil saturation at different time scales is established based on the minimum mean square error criterion $\mathrm{W}-\mathrm{H}$ algorithm, and the application pass rate exceeds $70 \%$ at different time scales; in 2015, $\mathrm{Li}$ Changzhi $^{[21]}$ et al. distributed SCS model was established in the Xiaoshui small watershed in Lishui, Hunan Province. The heavy rain process obtained from the

《Hunan Province Rainstorm and Flood Calculation Manual》 was used as input data, taking into account the rainfall in the basin, the soil moisture content at the basin scale, and the underlying surface factors such as the topography, vegetation and soil of the basin to obtain the critical rainfall of the dynamic early warning function of the study area; in 2015, Chen Yubin et al. ${ }^{[22]}$ used the impact rainfall in the early stage to replace the soil moisture content, and used whether the traffic exceeds the warning flow as an indication, constructing an API model of rainfall runoff. The model obtains the dynamic critical rainfall calculation function under different water content levels, and the final test yield rate reaches $94.7 \%$ can be used to calculate critical rainfall in similar watersheds with certain data conditions. Different researchers have the same idea for the estimation of dynamic critical rainfall, that is, based on the hydrological model calculation and analysis, the critical rainfall value corresponding to the peak flow of the outlet section of the basin reaches the preset value.

In 2017, Wang Lu et al. [23] attributed all the influencing factors of the river basin export flow to rainfall, and used the antecedent precipitation index to replace the soil miosture content, and regarded the previous impact rainfall, the current rainfall intensity and the current rainfall intensity as the whole influencing factors of the current flash flood. From the three influencing factors, constructed a composite rainfall indicator, and finally established a quantitative relationship between the composite rainfall indicator and the outlet section flow, so as to carry out the flash flood warning.

The rainfall runoff experience-related method is a conventional empirical method for studying rainfall runoff problems. It is a quantitative correlation diagram established by basing on the combination of causal analysis and statistics, using the average rainfall of each precipitation and the corresponding runoff, and the main factors affecting them ${ }^{[24]}$. Chen Yubin et al. ${ }^{[22]}$ constructing the API model for rainfall runoff to derive the dynamic critical rainfall of the study area .It is based on such methods. In 2017, Wang Jingwei ${ }^{[25]}$ used the water level flow back-calculation method and the design storm curve at different frequencies in the study area in the data-free area, and combined with the design flood to calculate the critical rainfall of the flash flood warning. In the same year, Ji Jing ${ }^{[26]}$ proposed using the design rainstorm as the input of Xinanjiang model and the SCS model, and compaed the peak flow of the output flood process with the disaster flow to obtain a reasonable critical rainfall. The value finally shows that Xin'anjiang model is more suitable for the critical rainfall demand in the study area. This method 
based on design storms and corresponding design floods is feasible to calculate the critical rainfall of mountain flood disasters in data-free areas.

In 2018, Zhang Silong ${ }^{[27]}$ proposed a critical rainfall index calculation based on the characteristic of heavy rain in a data-free area. He believes that the rainfall corresponding to the minimum level of flood occurrence in the five-year flood period is the critical rainfall of flash flood. And using the 《Atlas of Statistical Parameters of Chinese Rainstorms 》 to extract 5 kinds of design rains of $10 \mathrm{~min}, 1 \mathrm{~h}, 6 \mathrm{~h}, 24 \mathrm{~h}$ and $3 \mathrm{~d}$. He considered the rainfall corresponding to the maximum confluence time obtained by using the instantaneous geomorphic unit line is the critical rainfall of flash flood. Although the calculation method of critical rainfall based on the characteristic of heavy rain is complicated, if combined with the critical rainfall of flash flood cloud computing platform, it can easily obtain the critical rainfall of five-year flash flood in areas without data.

Through many literatures, it is shown that the critical rainfall in the data area can be estimated by statistical inductive method, or the water level flow back-calculation method based on distributed hydrological model (Xin'anjiang model, SCS model, TOPMODEL model) can be used to calculate the dynamic critical rainfall with high reliability and accuracy in research area. In the data-free area, the design heavy rain process can be obtained according to the 《Atlas of Statistical Parameters of Rainstorms 》 in the study area. After that, the corresponding flood process can be obtained by combining hydrological model, empirical formula or unit hydrograph method. We can also obtained the soil miosture content or the rainfall affected in the early stage based on hydrological model, empirical API formula or advance method firstly. And then the critical rainfall or dynamic critical rainfall can be obtained according to the specific rainfall runoff correlation method or rainstorm statistical parameter Atlas method.

\subsection{Water level warning index}

The water level warning index is obtained by analyzing the critical water level. He Bingshun et al. believe that the water level index has a strong physical concept and strong reliability. It is suitable for the flash flood-prone area, which is not directly related to mountain torrents or reservoir storage projects, underground rivers or snowmelting waters and so on ${ }^{[28,29]}$. The critical water level can be obtained by flood evolution methods and historical flood analysis methods. The corresponding water level in the upper and lower reaches method of the 《Technical Requirements for Analysis and Evaluation of Flash Flood Disasters $》$ refers to estimating the corresponding water level of the upstream water level station accroding to the control water level of the control section, and the early water level is used as an early warning. The water level of the upstream monitoring station corresponding to the downstream disaster level is the immediate transfer water level. However, the forecast period corresponding to the water level warning is relatively short. Due to the lack of time for the production of the flow, only the time of the flood evolution can be utilized. In order to extend the foreseeing period of the water level warning method, He Bingshun $^{[29]}$ proposed a method for detecting the rising rate of the water level, that is, making the time-water level curve of the flooding accroding to the historical flood data, and detecting the rising rate of the water level before preparing to transfer the water level. If the water level rise rate of the real-time storm flood is greater than the water level rise rate of the corresponding flood flood, and a flash flood warning is issued to ensure sufficient time for the transfer and evacuation work. The index of this early warning method can also be called the water level rising rate index.

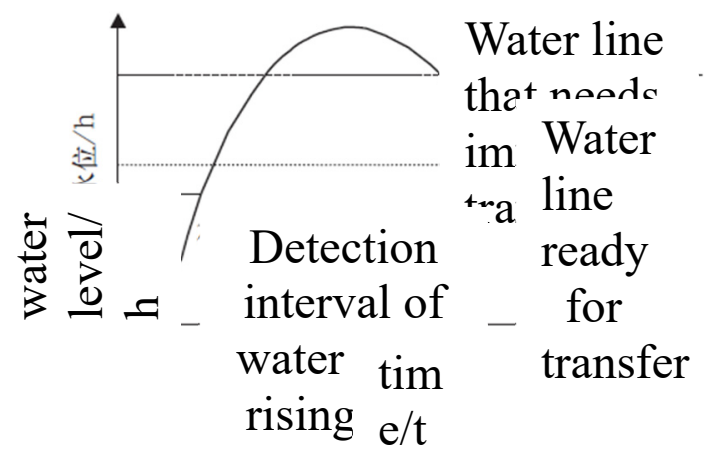

Fig. Detection interval of water level rising rate

\section{Conclusion}

The research on flash flood disaster warning has been a hot research issue in China for a dozen years. We have also obtained a series of research results. The research on flash flood disasters in China can be divided into three stages: the first stage is from 2000 to 2010 . In the beginning, there are many researches based on data-driven statistical induction. This method is characterized by not paying attention to the physical mechanism involved in the development of flash flood disasters, and directly estimating the critical rainfall from the series of measured rainfall data and the series of flash flood disasters data. This method is simple, easy to apply and requires relatively little data, but insufficient reliability. The second phase is from 2010-2015, China was inspired by the flash flood guidance (FFG) method developed by the US American Hydrological Research Center and began research on flood warning index, especially for dynamic critical rainfall index with considering of soil miosture content. This method which considers various factors and mechanisms of flood formation is realistic and the results are more convincing. The third stage is from 2015 to the present, and there are many researches on the critical rainfall of flash flood disasters in data-free areas, because most of the mountain flood-prone areas are in remote mountainous areas. The critical rainfall of flash flood in non-data areas without measured heavy rain data can be estimsted by using the 《Atlas of Statistical Parameters of Rainstorms》 and the rainfall runoff correlation method, which has certain guiding significance. 


\section{Reference}

1. The Ministry of Water Resources of the P. R. China. Bulletin of Flood and Drought Disasters in China (2016) [R]. Beijing: China Water Power Press, 2012.

2. Zhang $Z \mathrm{~T}$. The measures and effects of mountain torrent disaster prevention and control[J]. Water Resources and Hydropower Engineering, 2016, 47(01): 1-5+11.

3. Shang Q M, Huang X L. People oriented idea of flash flood disaster prevention[J]. Yangtze River, 2007, 38(6):6-8.

4. Ren H Y, Zou X, Zhang P C. Analysis of the causes of flash flood disasters in China[J]. China Water Resources, 2007, 14:18-20.

5. Shi P J. Theory and practice on disaster research $[\mathrm{J}]$. Journal of Nanjing University (Natural Science), 1991(11): 37-42.

6. Shi $\mathrm{P}$ J. THEORY AND PRACTICE OF DISASTER STUDY[J]. Journal of Natural Disasters, 1996, 5(4): 6-17.

7. Shi P J. Theory and practice on disaster system research in a third time[J]. Journal of Natural Disasters, 2002, 11(3):1-9.

8. Shi P J. Theory and practice on disaster system research in a fourth time[J]. Journal of Natural Disasters, 2005, 14(6): 1-7.

9. Shi P J. Theory and practice on disaster system research in a fifth time[J]. Journal of Natural Disasters, 2009, 18(05):1-9.

10. Wei Y M, Jin J L, Zhou C H, Wan Q, Li J R. A STUDY ON THE SYSTEM OF FLOOD DISASTER ESTIMATION[J]. Disaster Science, 1997 (03): 1-5.

11. Zhang T. Discussion on Causes and Prevention of Flash Flood Disasters[J]. China High Technology Enterprises, 2012(23):159-160.

12. Ding C M, He X F, Wan C Y. Cause Analysis and Prevention Countermeasures of Flash Flood Disasters in Zhejiang Province[J]. Yangtze River, 2010, 32(04):19-20.

13. Lin Y H. Cause Analysis and Prevention Measures of Flash Flood of Hezheng County[J]. Groundwater, 2017, 39(06):119-120+148.

14. Chen G Y, Yuan Y M. Research on critical precipitation amount computation method of mountain torrential flood disaster[J]. Yangtze River, 2005(12):40-43+54.

15. Li D, Chen G C, Xie P, Chen X, Yang D G, Qian J. Estimation of the Critical Runfall Resulting in Outburst of Floods and Debris Flows in the Ungauged Areas in Urumqi, Xinjiang[J]. Arid Land Geography, 2005(04):25-28.
16. Fan J Y, Shan J S, Guan M, Xu X S. Research on Analysis and Calculation Method of Critical Precipitation of Mountain Torrents in Jiangxi Province[J]. Meteorological Monthly, 2012, 38 (09): 1110-1114.

17. Cheng W S. A review of rainfall thresholds for triggering flash floods $[\mathrm{J}]$. Advances in Water Science, 2013, 24(06):901-908.

18. Ye Y, Wang Z N, Fan B Q. An analysis method for ascertain critical rainfall of mountain flood disaster of small watershed in ZheJiang Province[J]. JOURNAL OF CHINA HYDROLOGY, 2008(01):56-58.

19. Liu Z Y, Yang D W, Hu J W. DYNAMIC CRITICAL RAINFALL-BASED TORRENTIAL FLOOD EARLY WARNING FOR MEDIUMSMALL RIVERS[J]. Journal of Beijing Normal University (Natural Science), 2010, 46 (03): 317 321.

20. Ye J Y, Li Z J, Chang L. Research and Application pf Flash Flood Early Warning Method Based on Dynamic Critical Precipitation[J]. Meteorological Monthly, 2014, 40(01): 101-107.

21. Li C Z, Guo L, Liu C J, Sun D Y. Flash Flood EarlyWarning Indicators Based on Distributed Hydrological Model - A Case Study in South Branch of Censhui Watershed[J]. China Flood \& Drought Management, 2015, 25(01): 70-76+87.

22. CHEN Y B, YANG W F, XU Y S. Study of Dynamic Critical Precipitation Drafted Method under different soil moisture content level[J]. Yangtze River, 2015, 46(12): 21-26.

23. Wang L, Wang W C, Li H, Tian D, Shi J Y. Flash Flood Early Warning Method Based on Composite Rainfall Index and Its Application[J]. Express Water Resources \& Hydropower Information, 2017, 38(10): 32-36.

24. Bureau of Hydrology, Minister of Water Resource, the Yangtze River Commission. Hydrological information and forecasting manual[M]. Beijing: China Water Power Press, 2010: 313-320.

25. Wang J E. Dynamic Critical Rainfall Calculation of Flash Flood Warning in Ungaged Basin[J]. Water Resources Planning and Dsign, 2017(10): 53$56+59$.

26. Ji J, Liu P, Jiang Y S, et al. An Approach to Determine Critical Precipitation of Mountain Torrential Flood Disaster in Ungauged Basins[J]. China Rural Water and Hydropower, 2017(01): 76$79+83$

27. Zhang S L, Yi P, Xie S S. Research on Calculation Method of Flash Flood Critical Rainfall Based on Rainstorm Characteristics[J]. China Flood \& Drought Management, 2018, 28(02): 35-38. 
28. He B S, Guo L, Liu C J. Discussion on the Warning of Flash Flood[J]. China Flood \& Drought Management, 2018, 28(05):17-21+52.

29. He B S, Yan J H. Re-recognition of Flash Flood Water Level Warning[J]. China Flood \& Drought Management, 2016, 26(05): 61-63+99. 